\title{
Dynamics of Time Varying Volatility in Stock Returns: Evidence from Nepal Stock Exchange
}

\author{
Surya Bahadur Rana ${ }^{1}$ \\ Lecturer
}

Butwal Multiple Campus, Tribhuvan University, Nepal

\begin{tabular}{l} 
Article History \\
Received 04 April 2020 \\
Reviewed 12 May 2020 \\
Revised 20 May 2020 \\
Accepted 24 May 2020 \\
\hline Keywords \\
ARCH, GARCH, \\
GARCH-M, \\
TGARCH, EGARCH, \\
conditional volatility, \\
volatility persistence, \\
heteroscedasticity, shocks \\
\hline
\end{tabular}

Journal of Business

and Social Sciences

Research (ISSN: 2542-

2812). Vol V, No. 1, June

2020

\begin{abstract}
This study examines the properties of time varying volatility of daily stock returns in Nepal over the period 2011-2020 using 2059 observations on daily returns of NEPSE index series. The study examines various symmetric and asymmetric GARCH family models using several specifications of error distribution. The results of symmetric GARCH $(1,1)$ and GARCH-M (1, 1) models indicate that there is volatility persistence in daily returns on composite NEPSE index series over the sampled period. However, the estimated results for GARCH-M $(1,1)$ models show that the stock returns in Nepal offer no significant risk premium to hedge against risk associated with investment in stocks. The study also demonstrates that asymmetric $\operatorname{TGARCH}(1,1)$ and EGARCH $(1,1)$ models fail to capture the leverage effects on the volatility. Finally, study results show that GARCH $(1,1)$ with student's terror distribution model is the best fitted one to capture the volatility persistence of daily returns on NEPSE index series over the sampled period. The findings from this study offers an additional insight in understanding the volatility pattern of daily stock returns in Nepal for the most recent period that helps investors in forming a sound strategy to address the risk pattern of investing in stock market of Nepal.
\end{abstract}

\section{Introduction}

Volatility in stock returns is generally associated with risk of investment in the stock market. A careful examination of the volatility pattern of stock returns may offer an opportunity to capture significant profits for investors in the stock

\footnotetext{
${ }^{1}$ Dr. Rana holds a PhD degree from the Faculty of Management, Tribhuvan University, Nepal. He has published dozens of research papers in various journals. He can be reached at surryabrana@ gmail.com.
} 
market. Examining the properties of time varying volatility in financial time series has captured a great deal of empirical interests of academia and practitioners since the seminal work of Engle (1982) and Bollerslev (1986). Volatility refers to the uncertainty or variability in returns from an investment in financial assets. A financial time series is said to be volatile if its values change speedily from one period to other in an unpredictable fashion. The volatility in asset returns that varies across several time periods is called time varying volatility. The conventional econometric models assume that error terms are homoscedastic that they have constant variance and that they are independent of each other (Bollerslev, Chou, \& Kroner, 1992). However, Engle (2001) argues that most of the financial time series contain the time varying variance. In fact, time series are affected by their own past values (autoregressive), are dependent on past information (conditional) and have non-constant variance (heteroscedasticity). It implies that returns from financial assets, such as stocks, may demonstrate the periods of high and low conditional volatility at different points in time. Such volatility can be captured by applying alternative models dealing with time series heteroscedasticity. As Poon and Granger (2003) argue a good forecast of volatility in asset returns serves as the starting point for investment risk assessment. Therefore, it is necessary for the participants in the financial market to understand the behaviour of asset returns volatility for pricing and risk management of investment in financial assets.

In applied econometrics, the ordinary least squares (OLS) model is considered one of the great contributions as it allows for understanding and forecasting how one variable behaves in response to the change in other variables. Under OLS estimation, it is assumed that the expected value of the squared error term is the same at different points in time. However, if the variance of error terms is not same, though the regression coefficients of OLS estimates are still unbiased, the standard error and confidence intervals estimate become smaller giving inaccurate prediction. Therefore, it is also necessary to analyse and forecast the size of the errors in the models to generate greater forecast accuracy. Financial time series data, such as stock returns, contain some fundamental facts about the volatility (Miron \& Tudor, 2010). For example, the financial time series may exhibit a leptokurtic distribution with the value of kurtosis greater than 3 and has flat tails. Similarly, financial time series usually exhibits a volatility clustering, which implies that larger movement is followed by further larger movements and smaller movement is followed by further smaller movements over time. Similarly, financial time series also contain leverage effects. The existence of leverage effects implies that there is a negative relationship between movement in asset's price and volatility. With the presence of leverage effect, unfavourable shocks demonstrate larger effects on asset's price than equivalent favourable shocks (Black,1976). Besides, financial time series also demonstrates the pattern of long memory. It means that the volatility is highly persistent and the conditional variance shows near unit root behaviour. 
The existing body of literature on stock returns volatility takes the time varying conditional volatility into account. In examining the volatility of financial time series, a reference is made to the Autoregressive Conditional Heteroscedasticity (ARCH) model developed by Engle (1982). In ARCH model, the term 'autoregressive' refers the possible existence of autocorrelation in heteroscedasticity observed over different time periods, 'conditional' implies that the variance is dependent on past shocks, and, 'heteroscedasticity' implies that the time series demonstrates unequal variance over the period. As a good alternative to OLS, ARCH model considers heteroscedasticity as a variance to be modelled rather than treating it as a problem (Engle, 2001). It does so by predicting the variance of each error term. An extension of the ARCH model is proposed by Bollerslev (1986), which is known as Generalised Autoregressive Heteroscedasticity (GARCH) model. The empirical application of the GARCH model is spreading widely due to its efficiency in providing parsimonious estimates with few parameters as opposed to over-parameterized estimates of $\mathrm{ARCH}$. The ARCH/GARCH family models are used to describe and analyse the dynamic behaviour of volatility in stock returns. These models do so by specifying the conditional mean and conditional variance equations. However, the GARCH model also has one limitation that it cannot account for leverage effect. As a result, the literature on stock returns volatility proposes a number of extensions of the standard GARCH model. For example, GARCH-M model, EGARCH model (Nelson, 1991), and GJR-GARCH model (Glosten, Jagannathan, \& Runkle, 1993) also known as TGARCH model are some of the extensions of standard ARCH/ GARCH model to capture the asymmetric behaviour of stock returns volatility.

In the GARCH-in-mean (GARCH-M) model, the conditional mean depends on its own conditional variance. This model explains the asset returns by modelling time varying risk premium. In the context of the stock market, both good and bad news cause the volatility in stock returns. There is a general tendency of larger changes followed by further larger changes and smaller changes followed by further smaller changes in stock returns. Besides, negative shocks in stock markets tend to have larger effects than the positive shocks of the same magnitude. Moreover, the negative shocks in the stock market have long memory effects as such that it takes the stock market longer time to assume its pre-shock level. Hence, the assumption of symmetrical distribution of stock returns usually does not hold true. In response to the asymmetrical distribution nature of stock returns, Nelson (1991) proposed an exponential distribution model called Exponential GARCH (EGARCH)model. EGARCH model captures the asymmetric effects by using logarithmic transformation of the conditional volatility. - Another specification to capture leverage effect is the Threshold GARCH (TGARCH) model used by Zakoian (1994). This model is used to identify the relationship between asymmetric volatility and stock returns, and also represents a flexible alternative to asymmetric $\mathrm{GARCH}$ family models.

The stock market in Nepal has demonstrated considerable growth over the last two and half decades and has experienced momentous ups and downs. The NEPSE index reached its all-time high of 1,888 points on July 27,2016 , which 
afterwards moved down to 1,188 points two year later in 2018. Higher fluctuations in the NEPSE index have created both risk and opportunities for investors. The notable fluctuations observed over the periods in the stock market of Nepal demand a need for appropriate modelling of stock market volatility to understand its volatility pattern and behaviour. Therefore, in this study, an attempt has been made to provide additional evidence on the volatility of stock returns in the context of Nepal by using the ARCH/GARCH family models. The study particularly seeks to investigate the volatility pattern of daily stock returns in Nepal over the period 2011-2020 by using both symmetric and asymmetric volatility models and also analyse the suitability of GARCH family models in capturing the facts about daily returns on NEPSE index over the period. The study basically attempts to deal with following issues: Do the stock returns in Nepal exhibit the presence of conditional volatility? Do the stock returns in Nepal demonstrate volatility persistence? Do the stock returns in Nepal offer a significant risk premium consistent to the level of risk associated? Is there any leverage effect on the conditional variance of stock returns in Nepal? Do any of the GARCH family models fit the best to capture volatility persistence of daily stock returns in Nepal?

The remainder of this study is organized as follows: Section II presents a review of related studies; Section III describes the data and methodology used in the study; Section IV provides empirical results and discussion; and finally, Section $\checkmark$ concludes the study.

\section{Literature Review}

There are two popular models used for analysing the volatility in stock returns. They are ARCH and GARCH models proposed by Engle (1982) and later on extended by Bollerslev (1986) and Nelson (1991), among others. Several investigations in empirical arena have revealed two important characteristics of financial time series of stock returns- flat tails and volatility clustering. The volatility clustering in stock returns series is evidenced by flat tails that are leptokurtic in distribution and the distribution of series is non-normal. These characteristics of financial time series imply that there is a tendency of larger changes in returns from financial assets that are followed by further larger changes, and smaller changes followed by further smaller changes of random direction. Literatures advocate that GARCH family models are able to capture such nature of volatility in financial time series.

Several empirical literatures (e.g., Akgiray, 1989; Pagan \& Schwert, 1990; Episcopos,1996, among others) in finance support the application of $\mathrm{ARCH} /$ GARCH models and their extensions in capturing the volatility pattern of financial asset returns. In earlier study, Akgiray (1989) shows that the GARCH model consistently outperforms other models in all sub-periods and under all evaluation measures whereas Pagan and Schwert (1990) support the EGARCH as the best model in contrast to nonparametric models. Similarly, Episcopos (1996), by modelling stock returns as an autoregressive process with time varying 
parameters and errors following an EGARCH process, demonstrates that first order autocorrelations are negatively linked to volatility and observes time varying volatility in sub-index betas. On the other hand, Reyes (1999), by using Schwert and Seguin (1990) methodology to examine the relationship between firm size and time-varying betas of UK stocks, finds no significant time-varying coefficient to explain both small and large firm stock indexes. This study provides significantly different beta estimates of GARCH effects from those obtained while ignoring conditional heteroscedasticity.

A unified framework used by Bekaert and Wu (2000) to investigate asymmetric volatility, leverage effects and volatility feedback for the market portfolio demonstrates a rejection of the pure leverage model and finds a support for a volatility feedback story. The study particularly indicates that volatility feedback at the firm level is improved by significant asymmetries in conditional covariances while asymmetries in conditional betas are not significant. With respect to the Indian stock market for the period spanning from January 1993 to march 2003, Kaur (2004) documents the evidence of time varying volatility in daily returns on Sensex and Nifty and reveals that asymmetrical GARCH models, namely $\operatorname{EGARCH}(1,1)$ and TARCH $(1,1)$, are better than both ordinary least square and symmetrical GARCH models.

In an attempt to examine the significance of the A-PARCH model, Karanasos and Kim (2005) use daily data on five East Asian stock markets, and the study results confirm the first order A-PARCH model and $\operatorname{GARCH}(p, q)$ model as the best fitted models. Similarly, Alberola (2007) analyses the regularities of daily stock returns series in the Spanish Energy Market in order to model volatility by using ARCH processes. The results suggest that the expected conditional stock returns have a significant and different relationship with its own conditional variance. In the process of examining the time-varying risk-returns relationship and the effect of institutional factors on volatility of the equity market in Bangladesh, Basher, Hasn and Islam (2007) show a significant relationship between conditional volatility and stock returns. However, the study also finds the risk-returns parameter to be sensitive to the choice of samples and frequencies of data. The study further reveals that the coefficient of the risk-returns parameter is negative and statistically significant. Although this result is not consistent to the portfolio theory, it is theoretically possible in emerging markets that investors may not demand higher risk premium if they are better able to bear the risk (Glosten, Jagannathan, \& Runkle, 1993). The study suggests that, as a policy to improve the operation of capital market, timely disclosure and dissemination of information to the investors on the performance of listed companies should be emphasised.

In the context of Nepal, G. C. (2008) models the volatility of daily returns series in Nepalese stock market consisting of 1297 observations from July 2003 to February 2009 using different classes of estimators and volatility models. The study particularly reveals strong evidence of time-varying conditional volatility and high persistence of volatility in the context of the stock market in Nepal. The 
results indicate no significant asymmetry in the conditional volatility of returns and establish the GARCH $(1,1)$ model as the best model for volatility modelling in the context of Nepal.

Similar types of evidence supporting GARCH family models have been documented in some recent studies. For example, Miron and Tudor (2010) compare several GARCH family models for U.S. and Romanian daily stock returns volatility corresponding to 2002-2010 periods. The results demonstrate that GARCH family models with normal errors do not capture fully the volatility in time series, while generalised error distribution (GED) and student's $t$ error explain better the conditional volatility. Further, the study observes that asymmetric GARCH models are better in capturing the presence of volatility in time series that are not captured by symmetric ARCH/GARCH models. In particular, as the study concluded, the EGARCH model exhibits lower forecast errors than other asymmetric GARCH models.

In an attempt to compare the performance of modelling asymmetry and persistence under the impact of sudden changes in the volatility of the Indian stock market using the framework of standard $\operatorname{GARCH}(1,1)$ and $\operatorname{GJR}-\mathrm{GARCH}(1,1)$ models, Kumar and Maheswaran (2012) observe significant reduction in the asymmetry and persistence in volatility while incorporated the regime shifts in models. The out-of-sample forecast used in the study particularly reveals that volatility models with regime shifts has more accurate forecasts than others. In a recent study, Alam, Siddikee, and Masukujjaman (2013) investigate the significance of ARCH model for forecasting volatility of the DSE20 and DSE general indices by using the daily data from December 1, 2001 to August 14, 2008 as in-sample set and from August 18, 2008 to September 10, 2011 as out-of-sample set. The study documents that current volatility in both stock index series have significant impact on the past volatility. The study jointly establishes both ARCH and PARCH as the best models for DSE20 index returns based on in-sample statistical performance, and the ARCH model as the best for DSE general index series.

In a more recent study, Hasan and Hady (2014) find TGARCH and EGARCH models as the best fitted models in the context of stock market in Egypt. Similarly, in studying the volatility pattern of Indian stock market using daily time series of closing prices of S\&P CNX Nifty Index for 2003-2012 periods, Banumathy and Azhagaiah (2015) find the evidence to support $\operatorname{GARCH}(1,1)$ and TGARCH $(1,1)$ estimations as the most appropriate models to capture the symmetric and asymmetric volatility, respectively. The study also provides the evidence of negative shocks having significant effect on conditional volatility using TGARCH $(1,1)$ model. Moreover, Boako, Agyemang-Badu, and Frimpong (2015), in the context of Ghana, exhibit some stylized characteristics of equity returns such as volatility clustering, peak (peakedness), and leverage effect consistent to those found with most advanced stock markets. The results show that shocks to the Ghana equity market are usually transient with minimal instances of persistence and confirm that EGARCH $(1,1)$ is superior in modelling the volatility of returns 
on the equity market for the study period. In modelling time varying volatility in the context of Indian stock markets using the symmetric and asymmetric GARCH models, Tripathy and Gil-Alana (2015) indicate that the volatility of stock returns is persistent and asymmetric. The study reveals that the model under generalised error distribution appears to be the most suitable one.

Cited literature works, thus, generally agree on the presence of conditional volatility and the volatility persistence in time series of stock returns. However, they show mixed evidence on offering the risk premium and on capturing the leverage effects. The differences in empirical evidence observed in cited studies are primarily due to the varying properties of stock returns movements from one stock market to another. Moreover, most of the evidence is associated with the stock markets of developed and emerging economies and little is known about the developing stock markets like in Nepal. Therefore, based on the extensive review of cited literatures, this study attempts to investigate the presence of both symmetric and asymmetric volatility in empirical time series of daily stock returns from the stock market in Nepal. For this, both symmetric and asymmetric GARCH models for conditional volatility are estimated using different specifications for the error term distribution to decide on the models that best capture the properties of conditional volatility of daily stock returns series in Nepal.

\section{Research Methods}

\section{Data Source}

For the purpose of modelling the time varying volatility of stock returns in Nepal, this study uses daily time series data on stock market index in Nepal. The data set on the stock market index consists of value weighted daily closing composite NEPSE index obtained from the database of Nepal Stock Exchange (NEPSE) Limited.-. The sample period extends from the $27^{\text {th }}$ of March 2011 to the $22^{\text {nd }}$ of March 2020 and includes 2059 data points of daily returns on composite NEPSE index series. Although trading history in NEPSE dates back to 1994, there is no verified source of data on daily closing composite NEPSE index series starting from this date. The official website of NEPSE offers daily composite NEPSE index series since the fiscal year 2003/04 in its various issues of annual reports. However, this study does not take into account the periods since 2003/04. The reason is that, in the history of the stock market in Nepal, major regulatory reforms started since 2007 with the enactment of Securities Act, 2007 to improve the ecosystem of the secondary market. Even after this period, the participation of institutional investors in the trading forum of NEPSE was very negligible and mostly captured by individual investors. The participation of institutional investors started at a bit increasing pace only after the enactment of Mutual Fund Regulation in 2010. Increasing participation of individual investors along with institutional investors such as mutual fund, pension fund and insurance fund after this period appeared to have contributed to the depth and breadth of NEPSE. This is the 
basic motivation of this study to cover the period after 2010. Hence, the study period has been confined from 2011 until the recent past.

For the purpose of investigating daily stock returns volatility in Nepalese stock market, daily returns on the composite NEPSE index have been generated using Equation (1).

$$
r_{t}=\ln \left(\frac{N E P S E_{t}}{N E P S E_{t-1}}\right)
$$

In Equation (1), $r_{t}$ is the returns on NEPSE index on day $t$; In is natural logarithm operator, NEPSE $E_{t}$ is the NEPSE index on day $t$ and NEPSE $E_{t-1}$ is the NEPSE index on day $t-1$.

\section{The Model}

This study uses autoregressive conditional heteroscedasticity (ARCH) family models popularized by Engle (1982) and extended by Bollerslev (1986) and Nelson (1981), among others. The basic ARCH model postulates that the time series contains a time-varying variance, which depends on lagged effects. ARCH family models have been popular in modelling the attitude of investors towards both expected returns and risk. The ARCH modelling is basically related to economic forecasting and measuring volatility and consists of a family of models such as ARCH, GARCH, GARCH-M, EGARCH, and TGARCH.

\section{The ARCH (q) Model}

The basic $\mathrm{ARCH}(q)$ model simultaneously examines both mean and variance of a variable using Equation (2) and (3).

Mean Equation: $\mathrm{r}_{\mathrm{t}}=\mu+\varepsilon_{\mathrm{t}}$

Variance Equation: $\sigma_{t}^{2}=\alpha+\sum_{i=1}^{q} \beta_{i} \varepsilon_{t-i}^{2} \ldots$ (3)

Equation (2) is the mean equation, which expresses the stock returns at period $t$ as the mean returns $(\mu)$ plus a white noise error term $\left(\varepsilon_{t}\right)$. The error terms are assumed to be normally distributed with zero mean and variance, $\sigma_{t}^{2}$. In Equation (3), error variance $\left(\sigma_{t}^{2}\right)$ is considered time-varying or heteroscedastic, and the distribution of error terms is conditionally normal. Equation (3) expresses the error variance as the function of a constant term $(\alpha)$ and lagged squared error $\left(\beta_{i} \varepsilon_{t-i}^{2}\right)$ where $\alpha>0$, and $0 \leq \sum_{i=1}^{q} \beta_{i}<1$. For the stability condition to hold, $\sum_{i=1}^{q} \beta_{i}$ $<1$, otherwise $\varepsilon_{f}$ will be explosive meaning that it continues to increase over time. When $\sum_{i=1}^{q} \ldots \beta_{i}>0$, the squared errors contain a positive serial correlation even though $\varepsilon_{t}$ themselves do not. If $\sum_{i=1}^{q} \beta_{i}=0$, there is no time varying volatility in the series. On the other hand, $\sum_{i=1}^{q}: \beta_{i}<1$ provides the evidence of the time varying volatility.

The ARCH $(q)$ model states that when a big shock happens in period $t-i$, it is more likely that the value of $\varepsilon_{t}$ will be bigger as well. That is, when $\varepsilon_{t-i}^{2}$ is large, 
the variance of the next innovation, $\varepsilon_{t}$, is also large. And, conversely, when $\varepsilon_{t-i}^{2}$ is small, the variance of the next innovation, $\varepsilon_{t}$, is also small. The ARCH model is naturally interesting in a sense that it uses errors to explain the volatility. These errors are called 'shocks' or 'news' or 'innovations.' The larger shocks represent greater volatility in the series. Volatility remains the key element in asset pricing theories, which has increased the popularity of $\mathrm{ARCH}$ models for modelling volatility in empirical finance.

Before estimating GARCH models, it is necessary to test for the presence of possible ARCH $(q)$ effects. In the absence of ACRH effects, it is not necessary to estimate GARCH models. To test for the presence of possible ARCH effects in the residuals, the generalized autoregressive representation of the squared residuals of the form shown in Equation (4) is used.

$\hat{\varepsilon}_{t}^{2}=\alpha+\sum_{i=1}^{q}: \ldots: \beta_{i} \hat{\varepsilon}_{t-i}^{2}+e_{t}$

In Equation (4), the presence of conditional volatility or $\mathrm{ARCH}$ effect in stock returns is tested by examining the significance of parameters $\beta_{i}$ against the null of no ARCH effects. The null hypothesis of no ARCH effect is stated as $-H_{0}: \beta_{1}=\beta_{2}=\beta_{3}=\ldots . .=\beta_{q}=0$.

\section{The GARCH $(p, q)$ Model}

After having confirmed the ARCH effects, the ARCH/GARCH models can be estimated. Though the ARCH and GARCH models are similar in many aspects there are some underlying differences between them. The basic $A R C H$ (q) models developed by Engle (1982) are difficult to interpret if they yield negative estimates of $\beta$ is. The GARCH model proposed by Bollerslev (1986) resolves this problem of negative coefficient estimates. The basic GARCH model includes lagged conditional variance terms as autoregressive terms whereas $A R C H$ models resemble more of the moving average (MA) specification than an autoregression (AR). If moving average components in ARCH specification becomes too large, the estimation accuracy is lost. On the contrary, GARCH specification is based on few parameters to capture long lagged effects, which makes GARCH model parsimonious. The ARCH model basically does not explain the causes of variation in a financial time series, rather it explains the behaviour of conditional variance in a mechanical way. Therefore, this study uses different variations of GARCH family models, instead of basic ARCH models, to capture the nature of variation in stock returns. The standard $\operatorname{GARCH}(1,1$,$) model can be specified$ as in Equation (5).

$\sigma_{t}^{2}=\alpha+\theta_{1} \sigma_{t-1}^{2}+\beta_{1} \varepsilon_{t-1}^{2}$

In Equation (5), $\alpha$ is a constant, $\theta_{1}$ is the coefficient of GARCH term with 1 lag, and $\beta_{1}$ is the coefficient of ARCH term with 1 lag. Thus, the GARCH model is the function of both $A R C H$ and $G A R C H$ terms. The basic $\operatorname{GARCH}(1,1)$ model is 
easier to estimate and performs well because there are only three parameters $\left(\alpha, \theta\right.$, and $\left.\beta_{1}\right)$, to estimate. The GARCH $(1,1)$ model can be extended to the $\operatorname{GARCH}(p, q)$ model, where $p$ represents the lagged term of conditional variance (GARCH terms) and $q$ represents the lagged terms of squared error (ARCH terms). The GARCH $(p, q)$ model is specified as in Equation (6).

$\sigma_{t}^{2}=\alpha+\sum_{k=1}^{p} \theta_{k} \sigma_{t-k}^{2}+\sum_{i=1}^{q} \beta_{i} \varepsilon_{t-i}^{2}$

The $\operatorname{GARCH}(p, q)$ model specification states that the conditional variance $\left(\sigma_{t}^{2}\right)$ at time $t$ depends both on the past values of shocks captured by lagged squared error term $\left(\varepsilon_{t-i}^{2}\right)$ and past values of it self $\left(\sigma_{t-k}^{2}\right)$. In Equation (6), for the stationarity condition to hold, $\theta_{1}+\beta_{1}<1$. The coefficients of ARCH term $\left(\beta_{1}\right)$ and GARCH term $\left(\theta_{k}\right)$ must be greater than zero to ensure that the conditional variance is always positive.

\section{The GARCH-M $(p, q)$ Model}

As the investment theories postulate, risk-averse investors always demand a premium against risky investment and the amount of premium is positively associated with the level of investment risk. If the risk is captured by the volatility, then the conditional variance may enter the conditional mean function of $r_{t}$. According to the GARCH-M $(p, q)$ model, the conditional mean is allowed to depend on its own conditional variance. Therefore, this model incorporates a time varying risk premium to explain asset returns in the form shown in Equation (7).

$r_{t}=\mu+\delta \sigma_{t}^{2}+\varepsilon_{t}$

The GARCH-M (p, q) model is stated as in Equation (8).

$\sigma_{t}^{2}=\alpha+\sum_{k=1}^{p}\left|\theta_{k} \sigma_{t-k}^{2}+\sum_{t=1}^{q}\right| \beta_{i} \varepsilon_{t-i}^{2}$

In Equation (7), is the coefficient of conditional variance representing the risk premium on holding risky assets.

\section{The TGARCH $(p, q)$ Model}

The standard GARCH model treats bad news $\left(\varepsilon_{\mathrm{t}-1}<0\right)$ and good news $\left(\varepsilon_{\mathrm{t}}\right.$ $\left.{ }_{1}>0\right)$ symmetrically meaning that their impact on asset volatility is the same. However, in financial markets, any news and events have strong and powerful influence on the decision making of investors making an asymmetric impact on stock returns. In other words, the impact of good and bad news on a financial asset or the market as a whole may be asymmetric. It is normally observed that good news in the financial market makes an asset enter into the state of tranquillity resulting in decline in volatility. Conversely, bad news in the financial market makes the asset enter into a state of turbulence resulting in an increase in volatility. To 
capture the asymmetric impact of good and bad news, Threshold GARCH (TGARCH) model has been devised by Zakoian (1994), which is similar to GJR-GARCH model of Glosten, Jagannathan, and Runkle (1993). This model adds a multiplicative dummy variable into the variance equation to capture asymmetries in terms of negative and positive shocks. The addition of dummy variables allows us to verify whether the negative shocks make statistically significant differences.

The conditional variance specification for a $\operatorname{TGARCH}(p, q)$ model is stated in Equation (9).

$\sigma_{t}^{2}=\alpha+\sum_{k=1}^{p} \square \theta_{k} \sigma_{t-k}^{2}+\sum_{t=1}^{q} \square\left(\beta_{l}+\gamma_{t} D_{t-i}\right) \varepsilon_{t-i}^{2}$

In Equation (9), $D_{t}$ takes the value of 1 for bad news and 0 otherwise. Thus, inclusion of $D_{t}$ helps in incorporating different impacts of good news and bad news. The impact of good news is explained by $\beta_{i}$ and that of bad news by $\beta_{i}+\gamma_{\mathrm{i}}$ The is an asymmetry term, $\gamma>0$ where represents the asymmetry $\gamma=$ 0 and represents the symmetry. The significant and positive value of $\gamma$ implies that negative shocks will have larger impact on conditional variance than the equivalent level of positive shocks.

\section{The EGARCH $(p, q)$ Model}

Exponential GARCH (EGARCH) model developed by Nelson (1991) is similar to TGARCH model that captures the leverage effects of shocks on the financial markets. This model also allows for testing for asymmetries by using log of the variance series. The conditional variance for the $\operatorname{EGARCH}(p, q)$ model is specified in Equation (10).

$\log \left(\sigma_{t}^{2}\right)=\alpha+\sum_{i=1}^{q}\left|\beta_{i}\right| \frac{\tau_{t-1}}{\sigma_{t-1}}\left|+\sum_{i=1}^{q}\right| \gamma_{t}\left|\varepsilon_{t-1}\right|+\sum_{k=1}^{p} \mid \theta_{k} \log \left(\sigma_{t-k}^{2}\right)$

In Equation (10), $\log \left(\sigma_{t}^{2}\right)$ is the log of variance series, which makes the leverage effect exponential rather than quadratic. It ensures that the estimates are nonnegative. Similarly, the $\alpha$ represents the constant, $\beta_{i}$ represents the ARCH effects, $\gamma_{i}$ represents the asymmetric effects, $\theta_{k}$ and represents the GARCH effects. If $=$ $\gamma_{1}=\gamma_{2}=0$, the model is said to be symmetric. On the other hand, if $\gamma_{i}<0$, it implies that bad news generates larger volatility than good news.

\section{Diagnostic Checking of the Models}

The literature postulates that a good model should have least number of parameters, significant ARCH and GARCH coefficients, high adjusted R-square, high log-likelihood ratio, lowest AIC and SIC, no heteroscedasticity and no autocorrelation. Based on these criteria, the diagnostic checking has been conducted for all estimated models under three GARCH model error constructs, namely normal Gaussian distribution, student's $t$ distribution and generalised error distribution (GED). 


\section{Data Analysis and Discussions}

\section{Descriptive Statistics}

Before examining the volatility properties of daily returns on NEPSE index series and deciding on the best fitted model that captures the volatility pattern of daily returns series, it is necessary to specify the distributional properties of the returns series over the study period. Table 1 shows the descriptive statistics of daily returns on NEPSE index.

Table 1

Descriptive Statistics of Daily Returns on NEPSE Index

\begin{tabular}{llll}
\hline Mean & 0.000589 & Kurtosis & 7.452299 \\
Median & -0.000132 & Jarque-Bera & 1742.200 \\
S.D. & 0.012689 & p-value & 0.0000 \\
Skewness & 0.347982 & $\mathrm{~N}$ & 2059 \\
\hline
\end{tabular}

The mean returns over the study period is positive, which indicates that NEPSE index has increased over the period. The skewness measures the degree of distortion from the normal distribution. The daily returns series over the study period is positively skewed. It implies that the tail on the right side of the distribution is fatter and hence does not follow the normal distribution. It can be further verified by observing the histogram of the returns-series in Figure 1, which shows the fatter right tail of the distribution. Moreover, kurtosis is greater than 3 implying that the distribution has positive excess kurtosis, and hence leptokurtic. Generally, a larger kurtosis indicates a higher level of risk associated with an investment. Kurtosis in excess of 3 indicates that there are high probabilities of extremely large and small returns. Table 1 also shows the Jarque-Bera (JB) test statistic for normality. The JB test statistic is significant at 1 percent level, which implies that returns are not normally distributed.

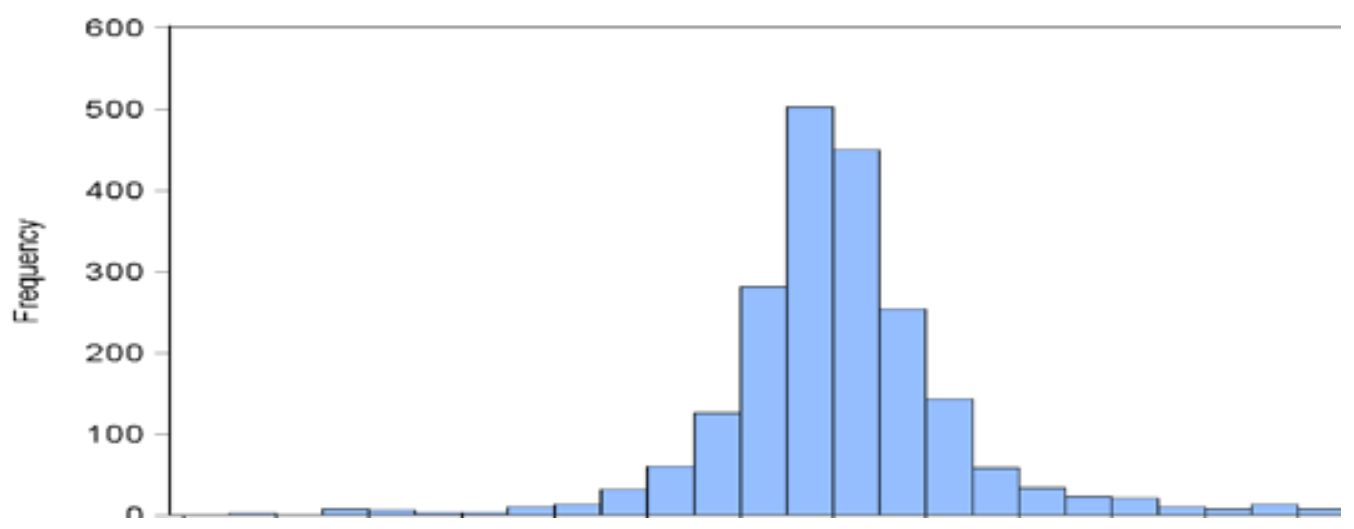

Figure 1: Histogram of Daily Returns on NEPSE Index 


\section{Volatility Clustering and Unit Root Test Results}

The level series of NEPSE index over the study period is not stationary. Therefore, daily returns on NEPSE index series have been generated using natural logarithmic transformation of Equation (1). The plot of daily returns on NEPSE index in Figure 2 shows a clear pattern of volatility clustering meaning that larger changes in returns on NEPSE index are followed by further larger changes and smaller changes in returns are followed by further smaller changes. It implies that small volatilities are clustering together and so do the large volatilities. Particularly, the daily returns series vary around the constant mean but variance is changing over the time. Thus, Figure 2 shows the varying volatility pattern of daily returns series on NEPSE index.

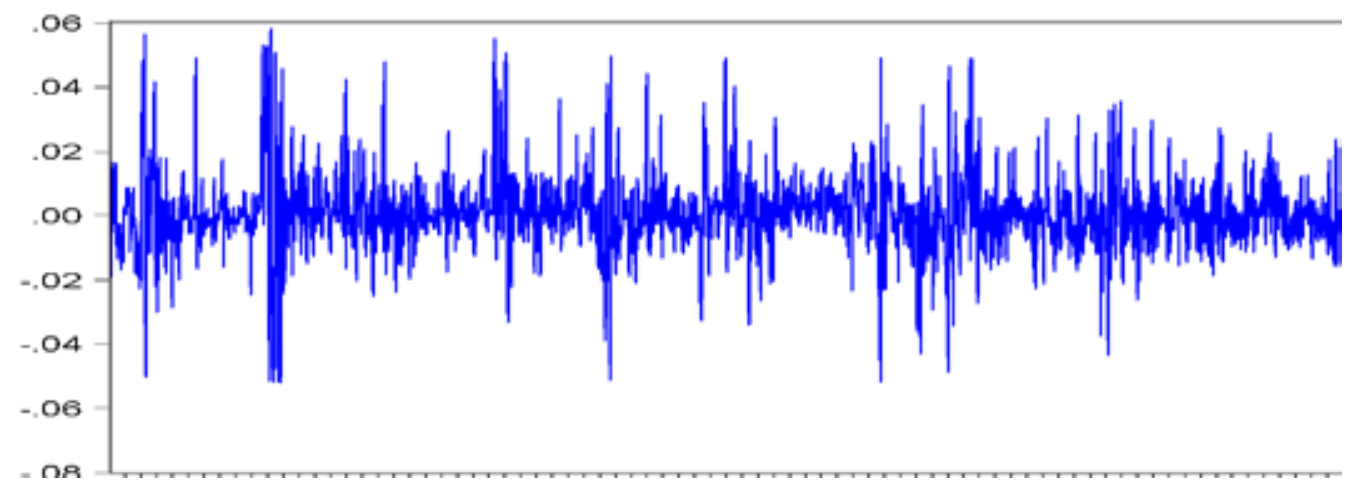

Figure 2. Volatility Clustering of Daily Returns on NEPSE Index

To confirm the stationarity in daily returns series, unit root test has been conducted. The unit root test applied in this study includes both Augmented Dickey Fuller (ADF) test proposed by Dickey and Fullerr (1979) and Philips-Perron (PP) test proposed by Phillips and Perron (1988). The results of unit root tests are reported in Table 2.

Table 2

Results of Unit Root Test of Daily Returns on NEPSE Index Series

\begin{tabular}{llll}
\hline & & ADF Test & PP Test \\
\hline t-Statistic & & $-30.446^{*}$ & $-36.537^{*}$ \\
Test critical & & & \\
values: & $1 \%$ level & -3.433 & \\
& $5 \%$ level & -2.863 & \\
& $10 \%$ level & -2.567 & \\
\hline
\end{tabular}

${ }^{*}$ Significant at $1 \%$ level.

As reported in Table 2, both ADF and PP test statistics are significant at 1 percent level. The test results provide sufficient evidence to reject the null of unit root. Hence, the daily returns series is stationary. 


\section{Results of ARCH Effects Test}

After having confirmed the volatility clustering and stationarity in daily returns series, it is further necessary to confirm the presence of $A R C H$ effects in the residual series. The presence of $A R C H$ effects is the necessary condition for running GARCH family models. The presence of $\mathrm{ARCH}$ effects has been tested using Lagrange Multiplier (LM) test. The results of ARCH- LM test are reported in table 3.

Table 3

Results of ARCH - LM Test on Residuals

\begin{tabular}{llll}
\hline F-statistic & 560.139 & Prob. F(1,2055) & 0.000 \\
Obs ${ }^{*}$-squared & 440.591 & Prob. Chi-Square(1) & 0.000
\end{tabular}

As revealed in Table 3, the ARCH - LM test statistic (440.591) is significant at 1 percent level, and hence there is sufficient evidence to reject the null of no ARCH effect. It implies that residuals of the daily returns series contain ARCH effects and therefore offer the sufficient reason for applying GARCH family modelling. This finding is consistent with the hypothesis that daily stock returns in Nepal exhibit the presence of conditional volatility over the study period.

\section{Results of Symmetric GARCH Models}

After having confirmed the volatility clustering, stationarity and $\mathrm{ARCH}$ effects, this study estimates the several GARCH family models. Table 4 shows the estimated results of symmetric GARCH models, namely GARCH $(1,1)$ and GARCH-M $(1,1)$ models. As the results indicate, the GARCH model parameters across all specifications of GARCH $(1,1)$ and GARCH-M $(1,1)$ models are statistically significant. Particularly, the constant $(\alpha)$, the coefficients of $A R C H$ terms $(\beta)$ and the coefficients of GARCH terms $(\theta)$ all are significant at 1 percent level.

The results of conditional variance equation reported in Panel B of Table 4 indicate that coefficients of GARCH terms $(\theta)$ are considerably larger than the coefficients of ARCH terms $(\beta)$ across all the specifications of $\mathrm{GARCH}(1,1)$ and GARCH-M $(1,1)$ models. It implies that daily returns on the NEPSE index have a long memory than one period and volatility to daily stock returns is more sensitive to the lagged values of stock returns than to the surprises and innovations in the market. These findings clearly establish the presence of time varying conditional volatility of daily returns on NEPSE index over the study period. The result also indicates that the persistence of volatility shocks, as represented by the sum of the coefficients of ARCH and GARCH terms $(\beta+\theta)$, is large. The sum of these coefficients is less than but nearer to 1. It implies that the effect of today's shock will remain in the forecasts of variance for many periods to come in the future. This finding is consistent with the hypothesis that daily stock returns in Nepal demonstrate the volatility persistence. The coefficients of risk returns parameters 
across many of the specifications are positive implying that there is a positive relationship between risk and returns. The estimated results of GARCH-M (1, 1) models, in mean equation, across several specifications of error distribution indicate that the coefficients of conditional variance (, though not significant, have no consistent signs. It implies that there is no significant impact of volatility on expected returns and there is lack of risk-returns trade-off over the period. Although the coefficients of conditional variance are not significant in the mean equation across all specifications of error distribution, its inclusion in the variance equation increases the significance of GARCH term. Overall, the estimated results of the GARCH-M $(1,1)$ model suggest that the risk premium is not significant to hold the risky stocks. This finding suggests that daily stock returns in Nepal do not offer a significant risk premium to hedge against the level of risk associated with investment.

Table 4

Estimated Results of GARCH $(1,1)$ and GARCH-M $(1,1)$ Models

\begin{tabular}{|c|c|c|c|c|c|c|}
\hline \multirow[t]{2}{*}{ Coefficients } & \multicolumn{3}{|c|}{$\operatorname{GARCH}(1,1)$} & \multicolumn{3}{|c|}{ GARCH-M $(1,1)$} \\
\hline & Normal & Student's t & GED & Normal & Student's t & GED \\
\hline \multicolumn{7}{|c|}{ Panel A: Mean Equation } \\
\hline Constant (Mean, $\mu$ ) & 0.0003 & 3.19E-05 & -0.001 & 0.0002 & 0.0001 & $-6.67 \mathrm{E}-05$ \\
\hline Risk Premium ( & & & & 1.0446 & -0.9902 & -0.9772 \\
\hline \multicolumn{7}{|c|}{ Panel B: Variance Equation } \\
\hline Constant (a) & $1.96 \mathrm{E}-05^{*}$ & $1.53 \mathrm{E}-05^{*}$ & $1.65 \mathrm{E}-05^{*}$ & $1.96 \mathrm{E}-05^{*}$ & $1.52 \mathrm{E}-05^{\star}$ & $1.64 \mathrm{E}-05^{\star}$ \\
\hline ARCH Effect $(\beta)$ & $0.3366^{*}$ & $0.3887^{\star}$ & $0.3713^{*}$ & $0.3373^{*}$ & $0.3861^{*}$ & $0.3692^{*}$ \\
\hline GARCH Effect () & $0.5436^{*}$ & $0.5635^{*}$ & $0.5485^{\star}$ & $0.5426^{*}$ & $0.5663^{*}$ & $0.5509^{*}$ \\
\hline$\beta+$ & 0.8802 & 0.9522 & 0.9198 & 0.8799 & 0.9524 & 0.9201 \\
\hline Adj. R2 & 0.0478 & 0.0472 & 0.0462 & 0.0473 & 0.0459 & 0.0446 \\
\hline Log Likelihood & 6498.92 & 6597.55 & 6586.34 & 6499.01 & 6597.66 & 6586.47 \\
\hline AIC & -6.3109 & -6.4058 & -6.3949 & -6.3100 & -6.4049 & -6.3940 \\
\hline SIC & -6.3059 & -6.3893 & -6.3785 & -6.2936 & -6.3858 & -6.3749 \\
\hline $\begin{array}{l}\text { ARCH-LM } \\
\text { (Heteroscedasticity) }\end{array}$ & 0.2539 & $8.57 E-06$ & 0.0023 & 0.2204 & 0.0032 & 0.0096 \\
\hline LB Q2(12) & 13.147 & 12.555 & 13.118 & 12.991 & 12.565 & 13.129 \\
\hline LB Q2(24) & 17.723 & 16.996 & 17.547 & 17.612 & 16.946 & 17.507 \\
\hline LB Q2(36) & 23.058 & 22.426 & 23.055 & 22.988 & 22.353 & 22.990 \\
\hline
\end{tabular}

Note. "' indicates that results are significant at $1 \%$ level.

Table 4 also shows the result of residual diagnostic check. The ARCH-LM test for heteroscedasticity indicates that there is no sufficient evidence to reject the null of no heteroscedasticity. Hence, residuals of all the estimated models are homoscedastic. Similarly, Ljung-Box Q-statistic of standardized squared residuals $\left(L B Q^{2}\right)$ for serial correlation reveals no problem of serial correlation in residuals up to 36 lags. Finally, the best fitted model among the several specifications of 
error distribution of symmetric GARCH $(1,1)$ and $\operatorname{GARCH}-\mathrm{M}(1,1)$ is selected based on log likelihood, AIC and SIC criteria. Among several models estimated in Table 4, the GARCH $(1,1)$ model with student's $t$ error distribution construct has the highest log likelihood, and the lowest AIC and SIC. So, this model explains best the time varying volatility associated with daily returns on NEPSE index over the study period.

\section{Results of Asymmetric GARCH Models}

In order to capture the leverage effects on daily returns on NEPSE index series, this study also estimates two asymmetric GARCH models, namely TGARCH (1, 1) and EGARCH $(1,1)$. Table 5 reports the estimated results.

Table 5

Estimated Results of TGARCH $(1,1)$ and EGARCH $(1,1)$ Models

\begin{tabular}{lllllll}
\hline Coefficients & \multicolumn{3}{c}{ TGARCH (1,1) } & \multicolumn{3}{c}{ EGARCH (1,1) } \\
\cline { 2 - 7 } & Normal & \multicolumn{2}{c}{ Student's t } & GED & Normal & Student's t GED \\
\hline Panel A: Mean Equation & & & & & & \\
\hline Constant (Mean, $\mu$ ) & 0.0002 & $-5.07 \mathrm{E}-05$ & -0.0002 & 0.0002 & $-8.55 \mathrm{E}-05$ & -0.0003 \\
Panel B: Variance Equation & & & & & \\
\hline Constant (a) & $1.97 \mathrm{E}-05^{*}$ & $1.48 \mathrm{E}-05^{*}$ & $1.62 \mathrm{E}-05^{*}$ & $-2.2151^{*}$ & $-1.7316^{*}$ & $-1.9589^{*}$ \\
ARCH Effect ( $\beta$ ) & $0.3095^{*}$ & $0.3304^{*}$ & $0.3196^{*}$ & $0.590^{*}$ & $0.6082^{*}$ & $0.6072^{*}$ \\
GARCH Effect () & $0.5443^{*}$ & $0.5706^{*}$ & $0.5542^{*}$ & $0.8052^{*}$ & $0.8582^{*}$ & $0.8346^{*}$ \\
Leverage Effect ( & 0.0522 & 0.1213 & 0.1075 & -0.0075 & -0.0471 & -0.0387 \\
$\beta$ + & 0.8538 & 0.9010 & 0.8738 & 1.3972 & 1.4664 & 1.4418 \\
\hline Adj. R2 & 0.0476 & 0.0467 & 0.0456 & 0.0475 & 0.0464 & 0.0452 \\
Log Likelihood & 6499.51 & 6599.27 & 6587.75 & 6490.08 & 6590.80 & 6580.78 \\
AIC & -6.3105 & -6.4065 & -6.3952 & -6.3013 & -6.3983 & -6.3885 \\
SIC & -6.2941 & -6.3873 & -6.3761 & -6.2849 & -6.3791 & -6.3693 \\
\hline ARCH-LM & 0.3148 & 0.0154 & 0.0250 & 0.0461 & 0.0031 & 0.0006 \\
(Heteroscedasticity) & & & & & & \\
LB Q2(12) & 13.815 & 13.335 & 14.040 & 14.413 & 12.434 & 13.643 \\
LB Q2(24) & 18.549 & 17.901 & 18.656 & 19.930 & 16.983 & 18.469 \\
LB Q2(36) & 23.872 & 23.270 & 24.121 & 24.344 & 21.687 & 23.220 \\
\hline
\end{tabular}

Note: "*' indicates that results are significant at $1 \%$ level.

In TGARCH $(1,1)$ estimates, the coefficients of leverage effect $(\mathrm{Y})$ across all the specifications are positive but not significant. It indicates that there is no leverage effect meaning that both negative and positive shocks of same extent have no significantly different effect on the conditional variance. Similarly, in EGARCH $(1,1)$ estimates, the leverage coefficients $(Y)$ across all the specifications are negative implying that there is negative correlation between past returns and future returns. However, the results are not statistically significant, and thus $\operatorname{EGARCH}(1,1)$ models also present the evidence of no leverage effect. Moreover, 
in all specifications of EGARCH $(1,1)$ models, the sum of ARCH and GARCH coefficients $(\beta+\theta)$ are greater than 1 and significant at 1 percent level. It implies that conditional variance is explosive.

The ARCH-LM test for heteroscedasticity shows no problem of heteroscedasticity in the residuals and LB $Q^{2}$ statistic shows no problem of serial correlation in the residuals. However, both the asymmetric models fail to capture the leverage effect. Hence, the negative and positive shocks show no different effects on daily returns of NEPSE index over the study period. Overall, the results support the hypothesis that there is no leverage effect on the conditional volatility of daily stock returns in Nepal and symmetric GARCH model, particularly GARCH $(1,1)$, model fits best to capture the properties of time varying conditional volatility of daily stock returns.

This study's findings associated with the presence of time varying conditional volatility and the volatility persistence of daily stock returns are consistent with most of the earlier findings. To quote some of them are Akgiray (1989), Pagan and Schwert (1990), Alberola (2007), and G. C. (2008), among others. However, this result contradicts with Reyes (1999), who documented no significant time varying coefficient for small and large firm stock indexes. With respect to the presence of leverage effects, the study results confirm to the findings of Akgiary (1989), Bekaert and Wu (2000), Karanasos and Kim (2005), and G. C. (2008), among others, and contradict with the findings of Pagan and Schwert (1990), Kaur (2004), Miron and Tudor (2010), Hasan and Hady (2014), and Boako, Agyemang-Badu, and Frimpong (2015), among others.

\section{Conclusion and Implications}

This study examined the properties of time varying volatility of daily stock returns in Nepal over the period from 27 th of March 2011 to $22^{\text {nd }}$ of March 2020 using 2059 observations on daily returns of composite NEPSE index series. The study examined various symmetric and asymmetric GARCH family models using several specifications of error distribution constructs such as Normal Guassian, Student's $t$, and Generalised Error Distribution (GED). The study specifically aimed to demonstrate the presence of conditional volatility and the volatility persistence of daily stock returns in Nepal. Besides, study was also concerned with examining whether or not the stock returns in Nepal offer a significant risk premium to hedge against the level of risk associated with investment. Moreover, study attempted to exhibit the leverage effect, if any, on the conditional variance of stock returns in Nepal. Finally, the study sought to detect among GARCH family models that best fit to capture volatility persistence of daily stock returns in Nepal. For the purpose of modelling, the time varying volatility of stock returns in Nepal, this study used daily stock returns on composite NEPSE index series obtained from the database of Nepal Stock Exchange (NEPSE) Limited. 
The estimated results for the presence of $\mathrm{ARCH}$ effects showed that the stock returns in Nepal exhibit the conditional volatility over the study period. The results of symmetric GARCH $(1,1)$ and GARCH-M $(1,1)$ models indicated that there is volatility persistence in daily returns on NEPSE index series over the sampled period. The presence of persistent volatility shocks in stock returns implies that today's shock remains in the forecasts of variance for many periods to come in the future. These findings are consistent with the many empirical documentations of earlier studies such as Akgiray (1989); Pagan and Schwert (1990); Alberola (2007); G. C. (2008), among others. The estimated results for GARCH-M (1, 1) models showed that the stock returns in Nepal offer no significant risk premium to hedge against holding risky stocks. The study also demonstrated that asymmetric $\operatorname{TGARCH}(1,1)$ and $\operatorname{EGARCH}(1,1)$ models fail to capture the leverage effects on the volatility. It implies that good and bad news have no significant different effects on the volatility of daily stock returns in Nepal over the study period. This result confirms the findings of earlier studies such as Akgiary (1989); Bekaert and Wu (2000); Karanasos and Kim (2005); and G. C. (2008), among others. Finally, study results revealed that the $\operatorname{GARCH}(1,1)$ model with student's $t$ error distribution construct is the best fitted one to capture the volatility persistence of daily returns on NEPSE index series over the sampled period.

The main implication of findings from this study is that it offers an additional insight in understanding the volatility pattern of daily stock returns in Nepal for the most recent period. A good forecast of volatility in the stock returns serves as the starting point for risk assessment and contributes for pricing and risk management of investment in stocks. Hence, investors can form a sound strategy to address the risk pattern of investing in stock market of Nepal. The basic construct of GARCH family models has been built up for modelling volatility associated with high frequency data to yield better results. Although trading history in Nepal Stock Exchange dates back to 1994, the sample period used in this study consisted of a limited range from 2011 to 2020 with 2059 daily data points. This study period was particularly selected to account for understanding the volatility pattern of daily stock returns in Nepal over the most recent period. Hence, the future study can be extended over a longer period of time to compare the volatility pattern of earlier period and most recent period in the context of daily stock returns in Nepal. Moreover, this study was limited to the use of univariate GARCH family models to capture the properties of daily stock returns volatility in Nepal. As literatures advocate, several macroeconomic variables are also responsible for stock returns volatility. These macroeconomic variables include gross domestic product, interest rate, inflation, exchange rate and many more. Capturing the volatility of stock returns including some of these macroeconomic variables requires using multivariate GARCH models. Therefore, future studies are suggested to incorporate some of these relevant macroeconomic variables to examine the volatility properties of stock returns in Nepal under multivariate GARCH model framework. 


\section{References}

Akgiray, V. (1989). Conditional heteroscedasticity in time series of stock returns: Evidence and Forecasts. Journal of Business, 62(1), 55-80.

Alam, M. Z., Siddikee, M. N., \& Masukujjaman, M. (2013). Forecasting volatility of stock indices with ARCH model. International Journal of Financial Research, 4(2), 126143. doi: $10.5430 /$ ijfr.v4n2p126

Alberola, R. (2007). Estimating volatility returns using ARCH models: An empirical case: The Spanish energy market. Lecturas de Economia, 66, 251-276.

Basher, S. A., Hasan, M. K., \& Islam, A. M. (2007). Time varying volatility and equity returns in Bangladesh stock market. Applied Financial Economics, 17, 1393-1407. doi: 10.1080/09603100600771034

Bekaert, G., \& Wu, G. (2000). Asymmetric volatility and risk in equity markets. The Review of Financial Studies, 13(1), 1-42.

Banumathy, K., \& Azhagaiah, R. (2015). Modeling stock market volatility: Evidence from India. Managing Global Transitions, 13(1), 27-42.

Black, F. (1976). The pricing of commodity contracts. Journal of Financial Economics, 3(1-2), 167-179.

Boako, G., Agyemang-Badu, A. A., \& Frimpong, J. M. (2015). Volatility dynamics in equity returns: A multi-GARCH approach. European Journal of Business and Innovation Research, 3(4), 36-45.

Bollerslev, T. (1986). Generalized autoregressive conditional heteroscedasticity. Journal of Econometrics, 31(3), 307-327.

Bollerslev, T., Chou, R. Y., \& Kroner, K. F. (1992). ARCH modeling in finance: A review of the theory and empirical e vidence. Journal of Econometrics, 52(1-2), 5-59.

Dickey, D. A. \& Fuller, W. A. (1979). Distribution of the estimators for autoregressive time series with a unit root. Journal of the American Statistical Association, 74(366), 427-431.

Engle, R. F. (1982). Autoregressive conditional heteroscedasticity with estimates of the variance. Econometrica, 50(4), 987-1007.

Engle, R. F. (2001). GARCH 101: The use of ARCH/GARCH models in applied econometrics. Journal of Economic Perspectives, 15(4), 157-168.

Episcopos, A. (1996). Stock return volatility and time varying betas in the Toronto Stock Exchange. Quarterly Journal of Business and Economics, 35(4), 28-38.

G. C., S. B. (2008). Volatility analysis of Nepalese stock market. The Journal of Nepalese Business Studies, 5(1), 76-84.

Glosten, L. R., Jagannathan, R., \& Runkle, D. E. (1993). On the relation between the expected value and the volatility of the nominal excess return on stock. Journal of Finance, 48(5), 1779-1801.

Hasan, D., \& Hady, A. (2014). Modeling volatility with GARCH family models: An application to daily stock log-returns in pharmaceuticals companies. Pensee Journal, 76(9), 52-69. 
Karanasos, M., \& Kim. J. (2005). A re-examination of the asymmetric power ARCH model. Journal of Empirical Finance, 13, 113-128. doi: 10.1016/ jempfin.2005.05.002.

Kaur, H. (2004). Time varying volatility in the Indian stock market. Vikalpa, 29(4), 25-42.

Kumar, D., \& Maheswaran, S. (2012). Modeling asymmetry and persistence under the impact of sudden changes in the volatility of the Indian stock market. IIMB Management Review, 24, 123-136.

Miron, D., \& Tudor, C. (2010). Asymmetric conditional volatility models: Empirical estimation and comparison of forecasting accuracy. Romanian Journal of Economic Forecasting, 3, 74-92.

Nelson, D. B. (1991). Conditional heteroscedasticity in asset returns: A new approach. Econometrica, 59(2), 347-370.

Pagan, A., \& Schwert, G. W. (1990). Alternative models for conditional volatility. Journal of Econometrics, 45(1-2), 267-290.

Phillips, P. C. B., \& Perron, P. (1988). Testing for unit root in time series regression. Biometrika, 75(2), 335-346.

Poon, S. H., \& Granger, C. W. J. (2003). Forecasting volatility in financial markets: A review. Journal of Economic Literature, 41(2), 478-539.

Reyes, M. G. (1999). Size, time varying beta, and conditional heteroscedasticity in UK stock returns. Review of Financial Economics, 8, 1-10.

Schwert, G. W., \& Seguin, P. J. (1990). Heteroscedasticity in stock returns. Journal of Finance, 45(4), 1129-1155.

Tripathy, T., \& Gil-Alana, L. A. (2015). Modeling time varying volatility in the Indian stock returns: Some empirical evidence. Review of Development Finance, 5, 91-97. doi: 10.1016/j.rdf.2015.04.002

Tsay, R. S. (2002). Analysis of financial time series. New York: John Willey \& Sons Inc. Retrieved from https://onlinelibrary.wiley.com/doi/book/10.1002/0471264105

Zakoian, J. M. (1994). Threshold heteroscedasticity models. Journal of Economic Dynamics and Control, 18(5), 931-944.

\section{Funding}

The author stated no funding or financial support was received in carrying out the research.

\section{Conflict of interest}

The author declared having no conflict of interest in the research work. 